\title{
The Small Vulnerable Newborn Series: Science for a Healthy Start
}

Invited comment to the Lancet, 16. August, 2020

Per Ashorn ${ }^{1}$, Robert E. Black ${ }^{2}$, Joy E Lawn ${ }^{3}$, Ulla Ashorn ${ }^{1}$, Nigel Klein ${ }^{4}$, Justus Hofmeyr ${ }^{5}$, Marleen Temmerman ${ }^{6}$, Sufia Askari ${ }^{7}$

${ }^{1}$ Center for Child Health Research, Faculty of Medicine and Health Technology, Tampere University, Finland.

${ }^{2}$ Johns Hopkins Bloomberg School of Public Health, Baltimore, MD, USA

${ }^{3}$ MARCH Center, London School of Hygiene \& Tropical Medicine, UK

${ }^{4}$ Institute for Child Health, University College London, UK

${ }^{5}$ Department of Obstetrics and Gynaecology, University of Botswana, Botswana

${ }^{6}$ Centre of Excellence in Women and Child Health- East Africa, Aga Khan University, Nairobi, Kenya

${ }^{7}$ Child Health and Development, Children's Investment Fund Foundation, London, UK

Correspondence: Per Ashorn, Center for Child Health Research, Faculty of Medicine and Health Technology, Tampere University, Arvo Ylpön katu 34, FIN-33014 Tampere, Finland. Email: per.ashorn@tuni.fi, Phone: +358 407280354 


\section{Main text (789 words + 1 figure + figure legend)}

We welcome The Lancet 2020 Campaign $^{1}$ on child and adolescent health which calls for a renewed focus on children. With less than a decade remaining to achieve the United Nations Sustainable Development Goals, this is a timely reminder about an unfinished agenda, reiterating the centrality of child survival and wellbeing in global development. The covid-19 pandemic further highlights the need for increased attention to children. Although the disease itself is usually mild in children, health service disruptions and other indirect effects are likely to hit pregnant women, children and other vulnerable individuals hardest. ${ }^{2}$ The current pandemic is still young, but there is ample evidence of this phenomenon already, e.g. as in the reduced proportion of institutional deliveries and increased stillbirth and neonatal mortality rates in some Asian and European populations., ${ }^{3,4}$

Although mortality rates for children under the age of five years have declined markedly in the past 30 years, more than five million children still die annually. ${ }^{5}$ Almost half of these deaths now take place in the first month of life, reflecting the fact that progress in reducing neonatal mortality has been much slower than that for older children. Some countries, especially in sub Saharan Africa, have experienced increasing numbers of neonatal deaths over the last decade. Less visible, but as important, are an estimated 2.6 million third trimester stillbirths each year. ${ }^{6}$ An estimated 20 million babies are born annually with low birth weight $(<2500 \mathrm{~g})^{7}, 15$ million preterm ${ }^{8}$, and 23 million small-for gestational age (SGA). ${ }^{9}$ In addition to increased mortality, these children have a higher risk of chronic health problems throughout childhood, adolescence and adulthood ${ }^{10}$, resulting in loss of human capital, and ill health even for the next generation. Given these statistics, there is a compelling need for added investment in fetal and newborn health. 
Successful public health interventions are typically based on identifying the most vulnerable, delivering preventive and curative interventions, and monitoring progress. For fetal and newborn health, unfortunately, there are major knowledge and action gaps in all these domains. The oldest and best-known indicator of newborn vulnerability is low birth weight (LBW), but this simple definition of $<2500$ grams fails to distinguish the two main pathological processes that reduce newborn size, i.e. preterm birth ("born too soon") and fetal growth restriction ("grown too slow”). Importantly, the LBW definition excludes babies with a higher birth weight ( $\geq 2500$ grams) who are preterm or small-for-gestational age (SGA) and still have increased vulnerability to mortality and morbidity. Although national-level estimates have been published over the last decade for the prevalence of $\mathrm{LBW}^{7}$, preterm $\operatorname{birth}^{8}$, and $\mathrm{SGA}^{9}$, there are no unified estimates that assess these conditions together. Many environmental, maternal, and fetal risk factors have been associated with preterm birth ${ }^{11}$ or fetal growth restriction ${ }^{12}$, but lack of clarity on the measurement of exposures and outcomes, as well as limited evidence regarding causal pathways impede implementation of effective interventions. Silo-ed approaches have also been a challenge, such as simplistically considering LBW to be related to maternal nutrition, or preterm birth to be only an obstetric issue.

To support the Lancet 2020 campaign on child and adolescent health, and link to other important initiatives, we and an international consortium of scientists, practitioners and policymakers are working on a new Lancet series, focused on the "Small Vulnerable Newborn". The purpose of our consortium is to accelerate progress towards ending preventable stillbirths and neonatal mortality and reaching national and global targets for child health. Through clarification of the terminology and summarizing the current knowledge on small vulnerable newborns, we aim to provide a scientific basis for action and 
demand for national and global commitments to the provision of a healthy start to life for every baby.

The planned article series will describe the different small vulnerable newborn phenotypes (Figure 1), provide updated estimates for their individual and combined epidemiology, and holistically characterize biological pathways from known risk factors to fetal growth restriction or preterm birth. The articles will also summarise adverse outcomes associated with newborn vulnerability and provide an overview of effective interventions, their recommended delivery through antenatal contacts and their financial feasibility and estimated impact on infant mortality. All analyses will take into account prior and emerging evidence, such as the recent suggestion that covid-19- associated societal lock-down might reduce the prevalence of preterm birth. ${ }^{13}$ For the epidemiological update, we are seeking participation for collaborative analysis of data sets from various sources. Interested investigators and national authorities can find further information on https://lshtm.onlinesurveys.ac.uk/vulnerablenewborndata.

There is an urgent need for increased attention to maternal, fetal, and newborn health. The Lancet series focused on small vulnerable newborns will provide an evidence-based platform for inter-sectoral action and call for a broad accountability to protect this pivotal group. Every newborn deserves the chance to survive and thrive.

\section{Conflict of interest statement}

The production of the Lancet series described in this comment will be funded by Children's Investment Fund Foundation (CIFF), through grants to Dr. Ashorn, Dr. Black, and Dr. Lawn. 
Dr. Askari works as the director of child health and development at CIFF. Other authors declare no competing interests 


\section{References}

1. The Lancet. Join the Lancet 2020 Campaign on child and adolescent health. Lancet 2020;395:89

2. Roberton T, Carter ED, Chou VB, Stegmuller AR, Jackson BD, Tam Y, SawadogoLewis T, Walker N. Early estimates of the indirect effects of the COVID-19 pandemic on maternal and child mortality in low-income and middle-income countries: a modelling study. Lancet Glob Health. 2020 Jul;8(7):e901-e908. doi: 10.1016/S2214109X(20)30229-1. Epub 2020 May 12.

3. KC A, Gurung R, Kinney MV, Sunny AK, Moinuddin M, Basnet O, Paudel P, Bhattarai P, Subedi K, Shrestha MP, Lawn JE, Målqvist M. Effect of the COVID-19 pandemic response on intrapartum care, stillbirth, and neonatal mortality outcomes in Nepal: a prospective observational study. Lancet Glob Health. 2020 Aug 10:S2214109X(20)30345-4. doi: 10.1016/S2214-109X(20)30345-4.

4. Khalil A, von Dadelszen P, Draycott T, Ugwumadu A, O'Brien P, Magee L. Change in the incidence of stillbirth and preterm delivery during the COVID-19 pandemic. JAMA. 2020 Jul 10. doi: 10.1001/jama.2020.12746. Online ahead of print.

5. United Nations Inter-agency Group for Child Mortality Estimation (UN IGME). Levels \& Trends in Child Mortality: Report 2019, Estimates developed by the United Nations Inter-agency Group for Child Mortality Estimation. United Nations Children's Fund, New York, 2019.

6. Lawn JE, Blencowe H, Waiswa P, Amouzou A, Mathers C, Hogan D, Flenady V, Frøen JF, Qureshi ZU, Calderwood C, Shiekh S, Jassir FB, You D, McClure EM, Mathai M, Cousens S; Lancet Ending Preventable Stillbirths Series study group; 
Lancet Stillbirth Epidemiology investigator group. Stillbirths: rates, risk factors, and acceleration towards 2030. Lancet. 2016 Feb 6;387(10018):587-603. doi:

10.1016/S0140-6736(15)00837-5. Epub 2016 Jan 19. PMID: 26794078

7. Blencowe H, Krasevec J, de Onis M, Black RE, An X, Stevens GA, Borghi E, Hayashi C, Estevez D, Cegolon L, Shiekh S, Ponce Hardy V, Lawn JE, Cousens S. National, regional, and worldwide estimates of low birthweight in 2015, with trends from 2000: a systematic analysis. Lancet Glob Health. 2019 Jul;7(7):e849-e860. doi: 10.1016/S2214-109X(18)30565-5.

8. Blencowe H, Cousens S, Oestergaard MZ, Chou D, Moller AB, Narwal R, Adler A, Vera Garcia C, Rohde S, Say L, Lawn JE. National, regional, and worldwide estimates of preterm birth rates in the year 2010 with time trends since 1990 for selected countries: a systematic analysis and implications. Lancet. 2012 Jun 9;379(9832):2162-72. doi: 10.1016/S0140-6736(12)60820-4.

9. Lee AC, Kozuki N, Cousens S, Stevens GA, Blencowe H, Silveira MF, Sania A, Rosen HE, Schmiegelow C, Adair LS, Baqui AH, Barros FC, Bhutta ZA, Caulfield LE, Christian P, Clarke SE, Fawzi W, Gonzalez R, Humphrey J, Huybregts L, Kariuki S, Kolsteren P, Lusingu J, Manandhar D, Mongkolchati A, Mullany LC, Ndyomugyenyi R, Nien JK, Roberfroid D, Saville N, Terlouw DJ, Tielsch JM, Victora CG, Velaphi SC, Watson-Jones D, Willey BA, Ezzati M, Lawn JE, Black RE, Katz J; CHERG Small-for-Gestational-Age-Preterm Birth Working Group. Estimates of burden and consequences of infants born small for gestational age in low and middle income countries with INTERGROWTH-21st standard: analysis of CHERG datasets. BMJ. 2017 Aug 17;358:j3677. doi: 10.1136/bmj.j3677. 
10. de Mendonça ELSS, de Lima Macêna M, Bueno NB, de Oliveira ACM, Mello CS. Premature birth, low birth weight, small for gestational age and chronic noncommunicable diseases in adult life: A systematic review with meta-analysis. Early Human Development 2020;149, 105154.

https://doi.org/10.1016/j.earlhumdev.2020.105154

11. Goldenberg R Culhane JF Iams J Romero R, Epidemiology and causes of preterm birth. Lancet. 2008;371:75-84.

12. Bendix I, Miller SL, Elke Winterhager E. Editorial: Causes and Consequences of Intrauterine Growth Restriction. Front. Endocrinol., 15 April 2020 | https://doi.org/10.3389/fendo.2020.00205

13. Philip RK, Purtill H, Reidy E, Daly M, Imcha M, McGrath D, O’Connell NH, Dunne CP. Reduction in preterm births during the COVID-19 lockdown in Ireland: a natural experiment allowing analysis of data from the prior two decades. Non-peer reviewed medRxiv preprint, doi: https://doi.org/10.1101/2020.06.03.20121442. Posted June 5, 2020 
Figure 1 Schematic illustration of different newborn phenotypes. Only the green category denotes to babies who are not vulnerable. The surface areas for each category are not necessarily proportional to the actual numbers of babies born each year.

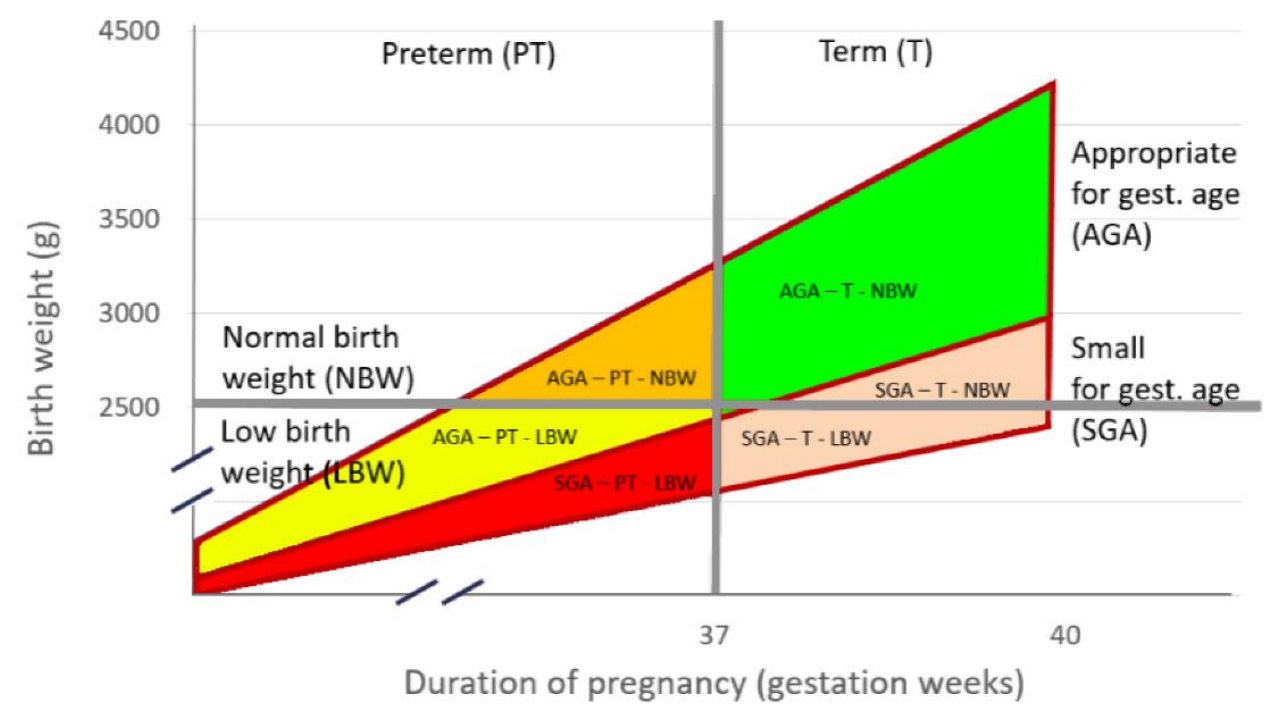

